\title{
Plant Generated Silver Nanoparticles and their Antibacterial Effect in Combination with Levofloxacin and Amikacin
}

\author{
SHAHNAZ MAJEED*1, MOHMMAD DANISH², NUR AALIYA BINTI KHAIRUDIN1 \\ and GOURI KUMAR DASH ${ }^{1}$ \\ ${ }^{1}$ Faculty of Pharmacy and Health Sciences, Universiti Kuala Lumpur, Royal College of \\ Medicine Perak, Malaysia-30450, Malaysia. \\ ${ }^{1}$ Malaysian Institute of Chemical and Bioengineering Technology, Universiti Kuala Lumpur, \\ Lot 1988, Kawasan Perindustrian Bandar Vendor, 78000, Alor Gajah, Melaka, Malaysia. \\ ${ }^{*}$ Corresponding author E-mail: shahnazmajeed5@gmail.com \\ http://dx.doi.org/10.13005/ojc/330636
}

(Received: October 13, 2017; Accepted: November 01, 2017)

\begin{abstract}
Nanotechnology has emerged as one the most prominent field of study among researchers nowadays and nanoparticles have the potential to be a viable and good option in combating bacterial resistance that has become a growing concern among health practitioners. Silver nanoparticles in particular have been in the spotlight due to its unique properties and excellent antimicrobial properties. Current study reported the synthesis of silver nanoparticles from the aqueous extract of Hibiscus sabdariffa plant belongs to family malvaceae. Addition of silver nitrate to cell free extract showed quickly change in color that indicates the production of nanoparticles. The UV-Visible spectroscopy analysis showed the absorption peak at $422.15 \mathrm{~nm}$ that confirms the presence of silver nanoparticles. TEM analysis revealed spherically shaped nanoparticle, well distributed with size ranges from $19 \mathrm{~mm}$ to $50 \mathrm{~mm}$. The synthesized silver nanoparticles showed good antibacterial effect when tested against Salmonella enterica, Escherichia coli, Bacillus cereus and Staphylococcus aureus. These nanoparticles showed good synergistic effect along with levofloxacin and amikacin.
\end{abstract}

Keywords: Silver, Nanoparticles, TEM, UV-vis spectrophotometer, Hibiscus sabdariffa, Levofloxacin, Amikacin.

\section{INTRODUCTION}

Over the past three decades, advanced technology and research had enabled nanotechnology to become one of the most active areas of research in modern science. This field basically deals with atoms or molecules that ranges between 1 to 100 $\mathrm{nm}$ in size. The manipulation of such atoms or molecules give rise to a better or completely new properties based on their size, shape, distribution and morphology of both its individual atoms/ molecules and their corresponding bulk ${ }^{1}$. These enhanced properties have enabled nanotechnology to gain attention and novel application in various fields 
such as health care, cosmetics, biomedical, food and feed, drug delivery, gene delivery, space industries, electronics and many other areas.

Among all metallic, organic and inorganic nanomaterials, metallic nanoparticles had been the most promising type as it contains large surface area to volume ratio that enables it to have a great antibacterial effect like silver, gold, copper, palladium, platinum and ruthenium. Among various metallic nanoparticles, silver nanoparticles had been gaining attention for its unique shape and size that enhances its properties such as effective anti-bacterial agent with lower toxicity, anti-fungal, anti-inflammatory, anti-angionesis and anti-platelet activity $^{2,3,4}$.

Generally, there are three ways to synthesize the nanoparticles to cater the demand of nanoparticles which are physical, chemical and biological method ${ }^{5,6}$. Among all the three methods, biological approach has emerged as a viable option. Usage of various biological resources such as plants, bacteria and fungi had shown to be a simpler, cost effective and most importantly environmentally friendly as there is no need to use high temperature, high pressure and harmful chemicals in the process ${ }^{7,8,9}$.

In this study, $H$. Sabdariffa plant leaves were used for the synthesis of silver nanoparticles and characterization was carried out by UV-Visible spectroscopy, TEM to confirm size, shape and distribution of nanoparticles. These silver nanoparticle were analysed for its antibacterial effect against various pathogens and compared with antibiotics were studied.

\section{MATERIALS AND METHOD}

\section{Collection of plant}

$H$. sabdariffa plant was bought from Tiang Nombor 9, Kampung, Rengit, Johor from a local who plant them commercially and was authenticated by botanist in Ipoh Malaysia.

\section{Preparation of extract}

The plant was washed with distil water to remove dirt and residue. Leaves are separated from the stem and left to dry under the sun for a week. The dried leaves are grinded using commercial grinder into powder form. The powder is transferred into $500 \mathrm{~mL}$ beaker. $4 \mathrm{~g}$ of the powder form was weighed and dissolved in $100 \mathrm{~mL}$ of distilled water in a $250 \mathrm{~mL}$ beaker and boiled for 10 minutes. The aqueous solution was filtered twice using filter paper to remove all the residue. The filtrate was kept in refrigerator for further use.

\section{Synthesis of silver nanoparticles}

The cell filtrate was taken out and kept as such for some time. $1 \mathrm{mM}$ silver was added dropwise and shaked it continuously. After that conical flask was covered with aluminium foil and put on the orbital shaker for 48 hours. Colour change is observed from dark yellow to light yellow which indicated formation of silver nanoparticles.

\section{Characterization of AgNPs}

The silver nanoparticle synthesized was subjected to JASCOV -650 UV-Vis spectrophotometric analysis in order to determine the absorbance (lambda max) range from 300 to $600 \mathrm{~nm}$.TEM analysis was used to determine the shape. size and dispersity of nanoparticles. For TEM (JEOL JEM) analysis sample was prepared by diluting the nanoparticle solution with distilled water. One drop of nanoparticle was put on carbon coated grid and subjected for TEM analysis

\section{Antibacterial Assay}

The nutrient agar media was used for the growth of bacteria and each agar plate was labelled and swabbed with selected pathogens (Bacillus cereus, Escherichia coli, and Salmonella enterica) to check the antibacterial effect of nanoparticles by using disc diffusion method. Each disc was impregnated with $40 \mu \mathrm{g}$ nanoparticles and compared with levofloxacin and amikacin. The petri dish is kept in incubator for overnight at $37^{\circ} \mathrm{C}$.

\section{RESULT AND DISCUSSION}

The aqueous extract of $H$.sabdariffa was used for the synthesis of silver nanoparticles. When the aqueous extract was challenged with silver nitrate colour change from dark brown into light brown colour Figure. $1^{10}$.

The reduction of silver ion into silver nanoparticles is confirmed by UV-Vis spectroscopy which is the common technique used for qualitative 
analysis of nanoparticles. It measures the surface plasmon resonance (SPR) peaks. with unique optical properties of nanoparticles due to Surface Plasmon Resosonance(SPR) of oscillation from the conduction of electrons which are in resonance with wavelength of irradiated light. (Bindhu M.R. and Umadevi M., 2013) 11,12
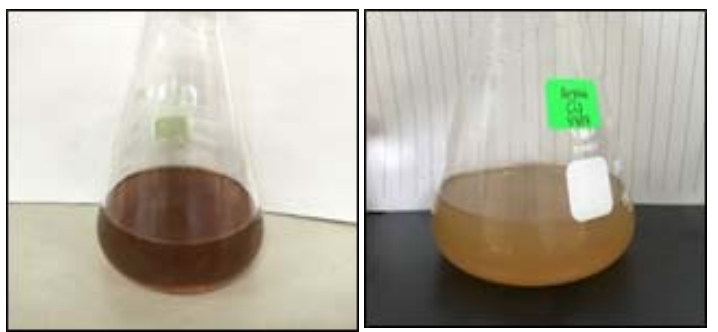

Fig. 1. Colour change of extract after addition of silver nitrate

Lambda mx .422.15nm
The UV-vis spectroscopy graph showed an absorbance peak at $422.15 \mathrm{~nm}$ which is specific for silver nanoparticles. Previous studies suggested spherical AgNPs have SPR peak between 410 to $450 \mathrm{~nm}$ Figure. $2^{11,12}$.

Transmission Electron Microscopy (TEM) is used to measure shape, size, distribution and morphology. TEM showed the AgNPs obtained are predominantly spherical in shape, well distributed with size ranges from $19 \mathrm{~nm}$ to $50 \mathrm{~nm}$ with an average of $30 \mathrm{~mm}$. Figure. 3 .

The antibacterial activity of biosynthesized silver nanoparticles were tested against four different human pathogens ie Salmonella enterica, Escherichia coli Staphylococcus aureus and Bacillus cereus respectively using disc diffusion

\section{Sample 1}

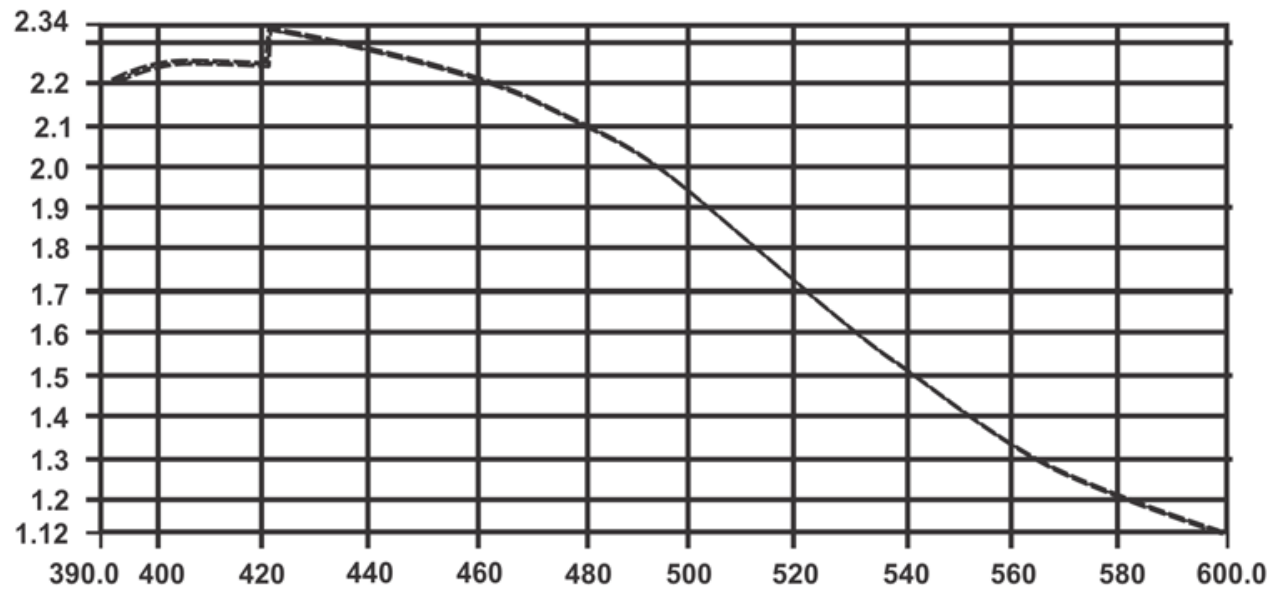

Fig. 2. UV-visible spectrum of Silver nanoparticles synthesized from Hibiscus sabdariffa

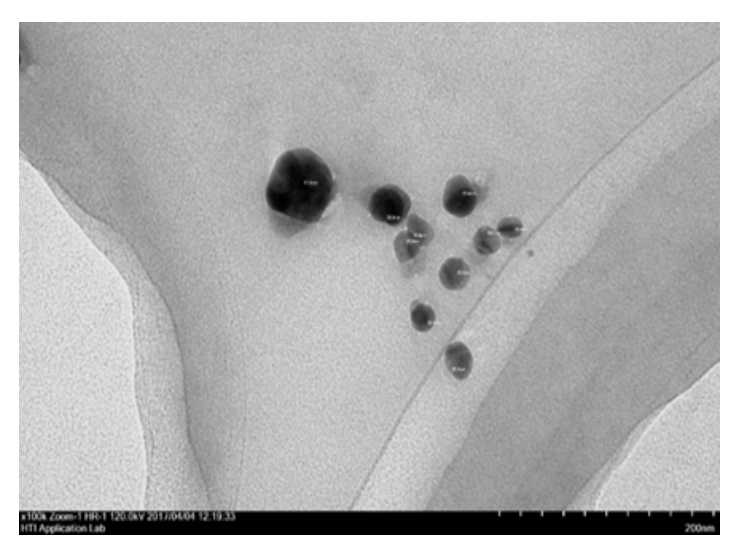

Fig. 3. TEM analysis showing the morphology of synthesized silver nanoparticles from $\boldsymbol{H}$. sabdariffa extract method. These nanoparticles were evaluate alone and also in combined form with amikacin and levofloxacin. Each blank disc was impregnated with $40 \mu \mathrm{g}$ of nanoparticles whereas for antibiotics each disc was impregnated with $20 \mu \mathrm{g}$ nanoparticles in order to find out the synergistic effect. These silver nanoparticles showed good antibacterial activity but also works better in combination with antibiotic and enhances their antibiotic efficacy. Among all the four pathogens $S$. enterica, $S$. aureus, and $E$. coli, showed the highest reading $40 \mathrm{~mm}$ in combination with Levofloxacin where as for synergistic effect with Amikacin, S. enterica and E. coli $35 \mathrm{~mm}$ gave the highest showed highest zone of inhibiton as shown in Table 1. Fig. 4 showed the graphical representation of combined effect of silver 
Table. 1: Zone of inhibition ( $\mathrm{mm}$ ) of synthesized nanoparticles in combination with antibiotics. (Am) Amikacin, (Levo) Levofloxacin

\begin{tabular}{lccccc}
\hline Pathogenns & AgNPs & Am & Am+ AgNPs & Levo & Levo+ AgNPs \\
\hline Salmonella enterica & 15 & 19 & 24 & 35 & 40 \\
Bacillus cereus & 16 & 21 & 27 & 21 & 26 \\
Staphylococcus aureus & 16 & 25 & 28 & 34 & 40 \\
Escherichia coli & 16 & 23 & 28 & 35 & 40 \\
\hline
\end{tabular}

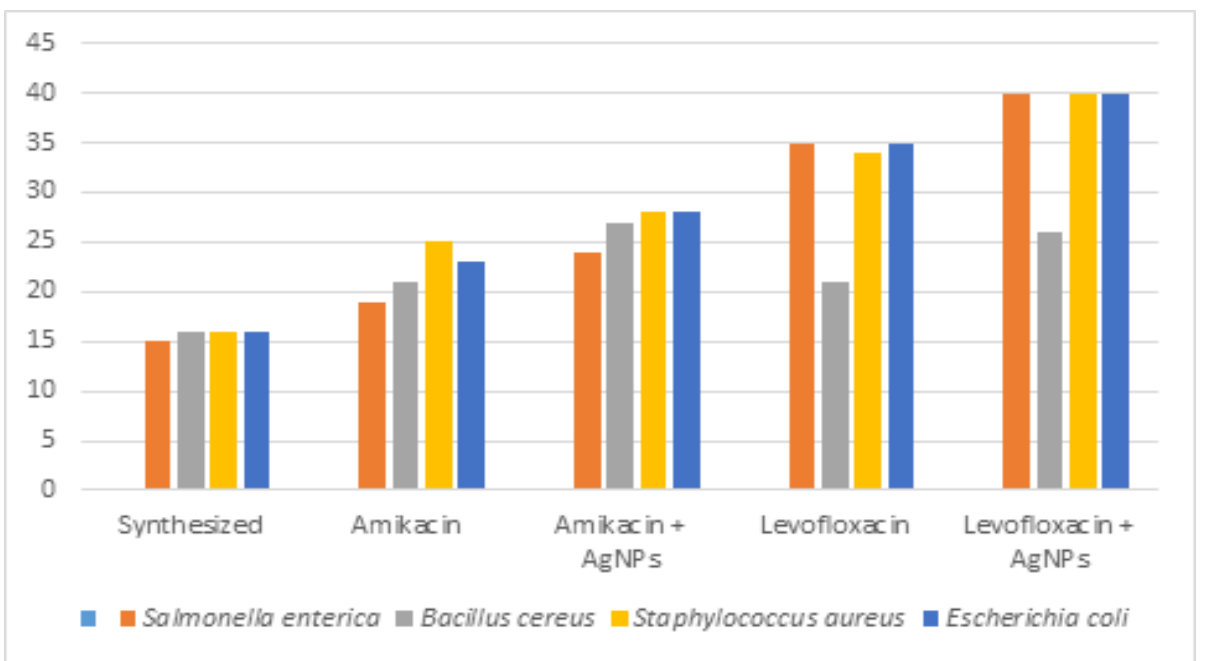

Fig. 4. Bar chart showing the effect of synthesized nanoparticles, antibiotic and antibiotic in combination with synthesized silver nanoparticles against human pathogens

nanoparticles with amikacin and levofloxacin. These silver nanoparticles have the efficacy to enter inside the cell and causing the cellular damage by inactivating the essential enzymes of the cell hence causing the cell death by generating the free radicals that plays active role for antibacterial effect $^{13,14,15}$

\section{CONCLUSION}

Hibiscus sabdariffa acts as a good source for the biosynthesis of silver nanoparticles and it showed good antibacterial activity against various pathogens. The synthesized silver nanoparticles also showed excellent synergistic combined effect when combined with levofloxacin and amikacin

\section{ACKNOWLEDGEMENT}

Author would thanks Centre of Research and innovative universiti Kuala Lumpur for providing financial assistance to carry out this study.

\section{REFERENCES}

1. Ahmed.S.; and Ikram.S.; Silver Nanomedicine \& Nanotechnology., 2015, 6, 309.

2. Ahmed, S .; Journal of Radiation Research and Applied Sciences,; 2016, 9, 1-7.

3. Kalashwaralal, K,; Deepak, V,; Pandian, K,; Kottaisamy, M,; Manikanth, SB, ;Karthikeyan,
B,; Gurunathan, S.; Coll Surf B: Biointerface. 2010, 77, 257-62.6

4. Monali, G,; Kesherwani, J,; Ingle, A,; Gade, A,; Rai, M.; Nanomedicine: Nanotechnology, Biology and Medicine.; 2009, 5, 382-86

5. Roco, C,; Nanopart Res,; 2005, 7, 707-12. 
6. Raveendran, P,; Fu, J,; Wallen. SL,; Virender, K,; Sharma, ;Rai A., Chem Soc,; 2003,125, 139- 40.

7. Goodsell, DS,; Wiley Liss. Hoboken. 2004.

8. Ingle, A,; Rai, M,; Gade, A,; Bawaskar, M., J Nanopart Res,; 2009, 11, 2079-85

9. Monali, G,; Kesherwani, J,; Ingle, A,; Gade, A,; Rai, M., Nanomedicine: Nanotechnology, Biology and Medicine.; 2009, 5, 382-86.

10. Sastry, $M$, ;Ahmad, A,; Islam Khan, M,; Kumar, R., Current Science,; 2003, 85, 162-70.

11. Mulvaney, $\mathrm{P}, ;$. Langmuir., 1996, 12, 788-800.
12. Chauhan, R., ; Reddy, A,; Abraham,; J, Applied Nanoscience., 2015, 5, (1) 63-71.

13. Yang, H,; Liu, C,; Yang, D,; Zhang, H,; Xi, Z; Journal of Applied Toxicology., 2009, 29(1), 69-78.

14. Pal, S,; Tak, Y, K.,; Song, J,M,; Applied \& Environmental Microbiology., 2007, 73(6), 1712-1720.

15. Rajan, A,; Cherian, E, ; Baskar, G,; International Journal of Modern Science and Technology., 2016, 1(2) 52-57. 